\title{
Context-sensitivity and the Preface Paradox for credence
}

\author{
Dominik Kauss $^{1}[(]$
}

Received: 2 June 2020 / Accepted: 9 March 2021 / Published online: 24 March 2021

(C) The Author(s) 2021

\begin{abstract}
It's intuitively plausible to suppose that there are many things that we can be rationally certain of, at least in many contexts. The present paper argues that, given this principle of Abundancy, there is a Preface Paradox for (rational) credence. Section 1 gives a statement of the paradox, discusses its relation to its familiar counterpart for (rational) belief, and points out the congeniality between Abundancy and broadly contextualist trends in epistemology. This leads to the question whether considerations of contextsensitivity might lend themselves to solving the Preface for credence. Sections 2 and 3 scrutinize two approaches in this spirit—one mimicking Hawthorne's (2002) Semantic Contextualist approach to an epistemic version of the Preface, the other one analogous to Clarke's (2015) Sensitivist approach to the doxastic version-arguing that neither approach succeeds as it stands.
\end{abstract}

Keywords Certainty $\cdot$ Closure $\cdot$ Consistency $\cdot$ Context-sensitivity $\cdot$ Probabilistic Coherence · Total Evidence

\section{The Preface for credence}

When absorbed in the practical and theoretical activities of our everyday lives rather than contemplating philosophical reasons for skepticism, at any given time there's loads of non-trivial propositions that we take for granted without harboring any doubt about their truth, propositions that we are not only highly but absolutely certain of. Potential examples are propositions about what our name and home address is; who our closest relatives are; what year it is; who's president at the moment; what country Paris is the capital of; whether or not New York City was struck by an islamist terror attack in the early 2000s; where we parked the car; what we had for breakfast; what our interlocutor just said a moment ago; whether or not we're currently visiting a zoo; whether or not back in college we were assaulted by someone who now is a nominee

\footnotetext{
$凶$ Dominik Kauss

kauss@em.uni-frankfurt.de

1 Goethe University Frankfurt, Theodor-W.-Adorno-Platz 1, 60323 Frankfurt am Main, Germany
} 
to the Supreme Court. Philosophers and conspiracy theorists may have their doubts as to how rational it is of us to engage in this practice, but that we do so is relatively uncontroversial.

Or at least it should be. One circumstance that has tended to obstruct philosophers' view of this mundane fact is the theoretical prevalence of the betting model of certainty, whose influence has only recently started to wane. On that model, certainty that $P$ requires a disposition to bet on $P$ at any odds (for many, see Maher 1993, pp. 133, 152; Kaplan 1996, pp. 91, 93; Christensen 2004, p. 21), which sets a criterion for certainty by which we hardly ever qualify as being certain of anything. Against this conception, Clarke (2013) argues convincingly that credences are context-sensitive in a way that undermines the model's descriptive adequacy: Even if the agent, $a$, is as certain that $P$ as you like, offering $a$ an extreme bet on $P$ 's truth changes what is at stake for $a$, by changing which possibilities are salient to and taken seriously by $a$, thereby reliably causing $a$ to lower their credence, at least by some small amount. Being certain that $P$ does not require a disposition to bet one's life on $P$, because being certain that $P$ does not require staying certain that $P$ under circumstances in which the question arises whether one should accept a bet on $P$ as extreme as that one. (See also Kauss 2020, p. 4507.$)^{1}$

Besides blinding its adherents to the pervasiveness of certainty, another effect the betting model has had on philosophy was amplifying the skeptical tendencies that come with the territory and cultivating a scarce view of rational certainty. After all, it doesn't seem particularly rational to be disposed to bet one's life on the truth of the proposition that one had oatmeal for breakfast. Fittingly, on this view, call it Scarcity, the only sort of propositions we could ever be rationally certain of are a priori insights such as logical, mathematical, and conceptual truths, and perhaps also phenomenological propositions about one's present experience. (In addition to Maher, Christensen, and Kaplan, as referenced above, among the many proponents of Scarcity are Foley 1992, p. 112f.; Eriksson and Hájek 2007, p. 209; Ganson 2008, p. 442; Sturgeon 2008, pp. 141, 150, 160f., 162 fn. 1; Frankish 2009, p. 79; Joyce 2009, p. 263; Demey 2013, p. 602; Greco 2013, p. 10; Leitgeb 2013, p. 1339; Ross and Schroeder 2014: p. 7ff.)

But even independent of Clarke's biting critique, Scarcity has never been entirely unchallenged. Arguing from a Pragmatist viewpoint, Levi (1983, p. 155) notoriously rejects the view as recommending neurosis rather than rationality. In a similar vein, one might argue that what it is rational to be certain of depends on context, for example on what is at stake for the agent; and that in many ordinary contexts the stakes are low enough for it to be rationally permissible to be certain that $P$. Think of Beddor's (2020) two-fold proposal that, first, it is rationally permissible for $a$ to be (psychologically) certain that $P$ iff it is (epistemically) certain that $P$; and second, that the truth-value of statements of epistemic certainty such as 'it is (epistemically) certain that $P$ ' depends

\footnotetext{
1 Note that Clarke's terminology differs from mine. I use 'certainty' and 'credence 1' to refer to the same mental state we are pre-theoretically acquainted with under various names, none of which has only one use or meaning, but one of which is 'certainty'; a state that could also be picked out in terms of belieffree from doubt, or, as some like to put it, full belief. In contrast, on Clarke's use of the term 'certainty', certainty is or requires stability of opinion. (See Clarke 2013: p. 11.) That use may be just as common and legitimate as the one intended here, but it does express a stronger condition, one that can be translated into present terminology in terms of stable/robust/resilient certainty. Anyway, due to his strong use, Clarke wouldn't put the above points in terms of 'certainty' but in terms of 'credence 1' or 'full belief'.
} 
on context, e.g. on the stakes. Put non-metalinguistically (ibid., p. 712): "while in some contexts precious little qualifies as epistemically certain, in ordinary contexts much more of our knowledge makes the cut." In sum, the recipe would be to adopt (Semantic) Contextualism about statements of epistemic certainty and, by extension, about ascriptions of rationally permissible (psychological) certainty. This would seem to support an abundant view of rational certainty:

(ABUNDANCY) There are many (a posteriori, non-phenomenological) propositions one can be rationally certain of. Or at least, being certain of those propositions (based on the available evidence, in the appropriate context) doesn't make one more irrational than one already is.

As this view finds more right in practice than Scarcity, the former enjoys a dialectical advantage over the latter in terms of argumentative burden.

One interesting fact about Abundancy is that it leads to a Preface Paradox for rational credence, at least when combined with a small set of rather attractive requirements on rational credence. Since its discovery by Makinson (1965), the Preface Paradox has primarily been phrased and studied as a paradox about rational belief. To see the structural kinship between doxastic and credal version, as a first stab let's start off by imitating the original's form as closely as possible, by simply replacing the notion of belief with the notion of certainty (credence 1). Assume that $a$ is certain of (at least) $n$ propositions, call them $a$ 's body certainties, each a posteriori and nonphenomenological, with $n$ being high.

(1) ( $a$ is certain that $P_{1}$ ) and ( $a$ is certain that $P_{2}$ ) and $\ldots a$ is certain that $P_{n}$.

Now consider that normal agents are not only fallible, but are aware of their fallibility. They know they have erred in the past, even under circumstances that in epistemic respect weren't worse than their present circumstances. Inductively, the record of their past errors, as well as of errors on the part of other agents like them, constitutes evidence that they are currently in error about something. In the light of these commonsensical considerations, $a$ adopts a stance of epistemic humility to the effect that

(2) $a$ is certain that at least one of the things they are certain of is false.

Although we will weaken this assumption in due course, let's go along with it for now in the interest of keeping the exposition simple. For further reference, call the proposition that (2) claims $a$ to be certain of $-\exists P\left(\left[\mathbf{C}_{a} P\right] \wedge \neg P\right)-a$ 's preface proposition. Not to turn the scenario into a variant of the Liar Paradox, let's assume that the quantifier in (the linguistic expression of) this proposition is restricted to $a$ 's body certainties, thereby excluding the Preface proposition from its own domain of quantification.

Note that, even with this restriction in place, there seems to be some sort of tension inherent in being certain that one of the things one is certain of is false. If we assume that $P_{1}, \ldots, P_{n}$ are mutually consistent, which we hereby do, the problem is not that $a$ 's set of certainties is inconsistent. After all, $a$ may be oblivious as to what exactly the contents of that set are; and the larger the set, the more likely such oblivion. But let us idealize a bit and assume that $a$ is aware of their body certainties, to the effect that

(3) $a$ is certain that, for all $P$, if they are certain that $P$, then $P$ is either $P_{1}$ or $P_{2}$ or ...or $P_{n}$, 
with the quantifier again restricted to the body subset of $a$ 's overall certainty set. Taking stock, the latter now comprises $a$ 's body propositions $P_{1}, \ldots, P_{n}$ per (1), $a$ 's Preface proposition $\exists P\left(\left[\mathbf{C}_{a} P\right] \wedge \neg P\right)$ per (2), as well as a corresponding inventory proposition $\forall P\left(\mathbf{C}_{a} P \rightarrow\left[P \equiv P_{1} \vee \ldots \vee P \equiv P_{n}\right]\right)$ per (3). The effect of assumption (3) is that it turns the tension felt with regard to (2) into an outright inconsistency. This brings $a$ into conflict with the norm of Consistency: ${ }^{2}$

(CONSISTENCY) If $P$ and $Q$ are mutually inconsistent, $a$ is rational only if $a$ is not both certain that $P$ and certain that $Q$.

One might think that the quandary can be dissolved by having $a$ simply drop their certainty that one of their certainties is false, or, equivalently, by rejecting (2) on the assumption that $a$ is rational. This strategy runs into the problem that, beside Consistency, another prima facie plausible requirement on the rationality of credal states is the following:

(Closure) If $P$ and $Q$ entail $R$, and $a$ is both certain that $P$ and certain that $Q$, then $a$ is rational only if $a$ is also certain that $R$.

Given (1) and (3), Closure predicts that $a$ is rational only if $a$ is certain that everything they are certain of is true. This however is precisely the stance of epistemic arrogance that $a$ wants no piece of. More to the point, the problem with being certain that all of one's certainties are true is that this attitude seems to be unjustified in terms of one's available evidence, and thereby to fly in the face of another prima facie plausible norm of rationality:

(TOTAL EVIDENCE) $a$ is rational only if $a$ 's credences are supported by $a$ 's evidence on balance.

Arguably, at least as far as halfway ordinary agents are concerned, being certain that all of one's certainties are true simply does not seem to be supported by one's evidence, let alone on balance. . $^{3,4}$

One sort of mindset one might be inclined to adopt towards this ramified dilemma is that the considered scenario should be acknowledged as a counter-example to the general validity of at least one of the above requirements on rationality: Contrary to what one may have thought, it turns out that Consistency, Closure, and Total Evidence

\footnotetext{
2 As used in the formulation and discussion of this and similar principles stating requirements on rationality, the term 'rational' will be short for 'perfectly rational' in an idealized sense excluding any room for improving the agent's performance in rational respect. The unsurprising fact that we fail this standard of rationality doesn't make those principles uninteresting. To the contrary. In general, the stronger the notion of rationality, the weaker the principle employing it, the higher the cost incurred by rejecting it. Therefore, if it can be shown that a candidate solution to the paradox requires us to abandon a principle as weak as those on display here, this detail would be key information in assessing the solution's success compared to competitors.

3 Some accept Total Evidence only for propositions that aren't self-evident, or propositions certainty in which isn't justified by default. Those who are so inclined are invited to read the norm as restricted accordingly. Since the proposition that all of one's certainties are true is hardly self-evident, and since certainty in that proposition is hardly justified by default, no restriction of the envisaged kind would affect the course of our discussion.

4 Unqualified uses of 'Closure', 'Consistency', and 'Abundancy' will refer to the certainty versions of Closure, Consistency, and Abundancy rather than to their well-known doxastic or epistemic counterparts.
} 
are not always normative for rational credence, at least not all three at once. This strategy is reminiscent of the Anti-Cogency approach to the doxastic Preface Paradox, which takes the latter as a refutation of Consistency and Closure for belief. (See Makinson 1965, 2012; Foley 1992; Christensen 2004; Sturgeon 2008; Easwaran \& Fitelson 2015.) Of course, as in the case of the belief version, in order to turn (1)-(3) into a potential challenge to either of those norms, we have to assume further that

(4) $a$ is rational.

Alternatively, instead of second-guessing any of our rational norms, one might feel the urge to raise an objection to one of our assumptions. It may be relatively innocuous to suppose, with (3), that $a$ can be rationally certain as to what they are certain of and what not (especially if the quantifier governing the inventory is restricted to a relatively manageable set). But (2) is less unsuspicious, given rationality assumption (4). How, one might wonder, could $a$ be rationally certain that one of their certainties is false? At least in the ordinary and ubiquitous sort of cases used to motivate the Preface, the kind of evidence that $a$ has for their Preface proposition is merely inductive/statistical, and it might be questioned whether evidence of this kind for $P$ could ever rationalize being certain that $P$. (See Thomson 1986; Kaplan 1996; Nelkin 2000, and Smith 2016.) This strategy echoes the Modalization approach to the doxastic Preface, arguing that it is not rational for $a$ to believe that one of their beliefs is false; rather, what $a$ should believe is that one of their beliefs might have been false (Ryan 1991), or that $a$ should believe that one of their beliefs might be false (Evnine 1999), or that $a$ should have a high credence that one of their beliefs is false (Kaplan 2013).

Be this as it may, we don't need a premise as strong as (2) to generate an apparent problem. Note that even though the statistical evidence $a$ has for $\exists P\left(\left[\mathbf{C}_{a} P\right] \wedge \neg P\right)$ may not suffice to make it rational for $a$ to be certain of this proposition, that evidence does seem sufficient to make it rational for $a$ to adopt some credence above zero in $\exists P\left(\left[\mathbf{C}_{a} P\right] \wedge \neg P\right)$. Given Complementarity, this is just to say that $a$ 's evidence makes it rational for $a$ to be less than certain that everything they are certain of is true. But this should already give us pause in light of assumptions (1), (3), and (4): $a$ 's adopting even the slightest non-zero certainty in $\exists P\left(\left[\mathbf{C}_{a} P\right] \wedge \neg P\right)$ is probabilistically incoherent with $a$ 's being simultaneously certain in each $P_{i}$. Arguably, violations of probability theory are not somehow less serious, in rational respect, than violations of logic. It thus seems that besides Consistency and Closure, another attractive "structural" requirement on the rationality of $a$ 's credal state is that it respect the probability calculus:

(COHERENCE) $a$ is rational only if $a$ 's credence function is probabilistically coherent.

Given Coherence for credence, Consistency and Closure for certainty become derivable, and violations of the latter two emerge as special cases of violating the former.

Let us then replace (2) with the significantly weaker assumption (subject to the same quantifier domain restriction) that

(2') $a$ has some degree of certainty above zero that at least one of the things they are certain of is false.

That is, $a$ 's Preface proposition is no longer assumed to be an element of $a$ 's certainty set, or (speaking in terms of an onion model of credence) of the innermost sphere of $a$ 's 
credal state, but is instead assumed to inhabit some sphere other than the outermost. The premise set (1),(2'),(3),(4) defines what I will call the Preface for credence. ${ }^{5}$

Whereas the Preface for belief is standardly viewed as a challenge to Consistency and Coherence for belief, both by those who consider the challenge as ultimately successful as well as by those who don't, the Preface for credence can with equal right be considered a challenge to Coherence for credence which, notably, is a widely shared commitment both among proponents of Modalization as well as among proponents of Anti-Cogency. (See Foley 1992, p. 113f.; Christensen 2013, p. 15ff.; Kaplan 2013, p. 5; Sturgeon 2008, pp. 149, 163 fn. 17; Easwaran \& Fitelson 2015, p. 71.) In this respect, the credal Preface cuts deeper than its doxastic cousin. True, Anti-Cogency and Modalization proponents are typically committed to Scarcity, and are thus disposed to reject (1) on rationality assumption (4). But without getting into a discussion about the arguments these philosophers and their Pragmatist and Contextualist opponents are in a position to offer for or against Scarcity-which for reasons of space we are unable to do here-let's just keep in mind that, for what it's worth, Abundancy seems to be the more commonsensical route to take.

Setting aside the betting model and the opposition to Abundancy it inspires, it is hard to see how one could consider the doxastic version paradoxical without assigning the same status to the credal version as well. The intuition of risk aggregation powering the doxastic Preface is that it's rational for $a$ to believe that some of their beliefs are false. The force of this intuition depends at least in part on the assumption that $a$ believes many (non-trivial) things, as ordinary agents normally do: Ceteris paribus, the larger the set of propositions $a$ believes, the greater the risk of believing a falsehood, and the more tempting said idea. If we follow the majority of participants to the Preface debate and give 'belief' a weaker reading than 'certainty', the set of propositions $a$ is certain of will presumably be smaller than the set of propositions $a$ believes, and will thus incur a lower risk of error than $a$ 's belief set. Intuitively, the hypothesis that one of the propositions in $a$ 's certainty set is false should therefore be less tempting — should appear less probable - than the hypothesis that one of the propositions in $a$ 's belief set is false. However, if $a$ is a halfway normal agent, $a$ 's certainty set won't be so small as to allow us to rule out completely its containing a falsehood. More plausibly, a positive probability remains that not everything $a$ is certain of is true. And intuitively, $a$ should be modest enough to acknowledge this, and accordingly adopt a non-zero degree of certainty in their Preface proposition, as (2') stipulates. ${ }^{6}$

\footnotetext{
5 Since $a$ 's Preface proposition is about $a$ 's set of body certainties $C$, and since, in order to think a proposition, one must be able to refer to (think of) whatever that proposition is about, the reader might wonder how $a$ is able to refer to $C$. The canonical way to refer to a set would be to use a name whose reference has been fixed by giving a list of the set's elements. Of course, if (2') is understood as presupposing that $a$ possesses such a list, (2') would entail inventory assumption (3), making the latter redundant and infecting (2') with (3)'s idealizing character. However, defining a set by listing its contents is only one method enabling one to refer to the set. Alternatively and more realistically, $a$ may be disposed to refer to $C$ by means of a definite description, picking out $C$ in terms of the subject matter of $C$ 's elements (e.g. 'my certainties about biology') or the time of their formation (e.g. 'my certainties acquired before college') or what have you. Since referring to a set descriptively is compatible with being less than fully informed as to the set's elements, (3) must be counted as an assumption in its own right.

6 The thrust of our discussion runs counter to a view one finds expressed quite frequently in the Preface literature, a view to the effect that the paradox resolves if only we redescribe the agent's mental state in
} 
Given Abundancy, rationality assumption (4) is consistent with (1) even where $P_{1}, \ldots, P_{n}$ go well beyond a priori and phenomenological truths. Accordingly, friends of Abundancy will urge that, if there is a way to block the argument from (1),(2'),(3),(4) to the rejection of Coherence, it won't consist in following the traditional tendency to identify rational certainty with what is indubitable from a radically skeptical point of view. In the light of the open-mindedness philosophers of a broadly contextualist orientation show towards Abundancy, one might recall that solutions to different versions of the Preface have been proposed that in one form or another make appeal to contextsensitivity of some kind. This makes it natural to ask whether one of those proposals could serve as a model for solving the Preface for credence. I will consider two such attempts, each constructed in analogy with a respective existing approach to some version of the Preface, the first being Hawthorne's (2002) Contextualist approach to an epistemic version, the second Clarke's (2015) Sensitivist approach to a more conventional doxastic version.

\section{Contextualism about rationality}

One way we might try to bring considerations of context-sensitivity to bear on the Preface for credence is to proceed in direct analogy with Hawthorne's Contextualist approach to an epistemic version of the Preface. The latter runs as follows. Consider a set of propositions $P_{1}, \ldots, P_{n}$ such that for each $P_{i}$ it is intuitively plausible to say that $a$ knows $P_{i}$. Now observe that it is much less intuitively plausible to say that $a$ knows the conjunction of all those $P_{i}$, given that $n$ is sufficiently high (even if we stipulate that $a$ is rational). But how can this be, assuming that some kind of Closure principle can

\footnotetext{
Footnote 6 continued

terms of credence rather than belief. Since the replacement of belief talk by credence talk is dear to the heart of Bayesians of a certain bent, that supposed resolution has been labeled the Bayesian solution to the Preface. (See Easwaran 2016.) With that said, the conditional claim just cited is not only endorsed by Bayesians but also by some of their opponents who refuse to abandon belief talk, such as Foley (1992, p. 121) and Cevolani 2017, p. 177). The latter writes:

It is then useful to see how a "purely probabilistic" analysis of the Preface Paradox would run (cf. Easwaran \& Fitelson 2015, Sec. 1.2). Suppose that our author has a high degree of belief in each of the claims $b_{1}, b_{2}, \ldots, b_{m}$ made in the book. If such degrees of belief are expressed as degrees of probability, then the probability calculus alone prescribes that the conjunction $b$ of those claims cannot be more probable than any of them. But this only means that the author will have a low degree of belief in $b$ or, equivalently, a high degree of belief in its negation, i.e. in the prefatory statement $\neg b$. Thus, no paradox arises, if we refrain from talking about belief or acceptance at all, and only take into account the degrees of belief, or credences, expressed by the relevant probabilities.
}

Based on the premise that $a$ has a high credence ("degree of belief") in each $P_{1}, \ldots, P_{n}$, Cevolani concludes that $a$ (if rational) will have a high credence in the negation of their conjunction. I of course agree that, given Cavolani's premise, his conclusion follows, assuming that in the context of both the premise and the conclusion 'high degree of belief' is short for 'high degree of belief but less than 1'. I also agree that there's nothing paradoxical about this argument or its conclusion. But I deny that the absence of paradox is achieved by means of avoiding belief talk and instead describing the agent's mental state in terms of credence. Rather, the absence of paradox is achieved by Cevolani's premise that $a$ 's credence in $P_{i}$ is high but less than 1. We on the other hand are interested in cases where $a$ 's credence in each $P_{i}$ is 1 . Ruling out from the start that such cases are compatible with the assumption that $a$ is rational would be to assume the falsity of Abundancy and thus beg the question. 
be expected to hold for knowledge? In the case of knowledge, several different such principles have been employed by philosophers, the simplest one being: If $P$ and $Q$ collectively entail $R$, and $a$ knows $P$ and knows $Q$, then (C) $a$ also knows $R$. Most see reason to qualify this principle by replacing consequent $(\mathrm{C})$ with a weaker condition, such as that (C') $a$ is rational only if $a$ also knows $R$; or that (C') $a$ is in a position to know $R$ (provided $a$ knows that $P$ and $Q$ entail $R$ ). For the purpose of sketching the epistemic Preface, it will be immaterial which of these Closure principles we assume.

Hawthorne (2002, p. 249ff.) suggests that Lewis' (1996, p. 554) analysis of knowledge (combined with a certain refinement of Lewis' Rule of Belief) enables us to solve the epistemic Preface. On that analysis, a knows that $P$ iff $a$ 's evidence eliminates every relevant possibility in which not- $P$; relevant, that is, not necessarily in $a$ 's context but in the context in which $a$ 's knowledge is being appraised. Which possibilities count as relevant and thus cannot be properly ignored in appraising $a$ 's knowledge can change from context to context, and accordingly so can the answer to the question whether $a$ knows that $P$. Utilizing this apparent shiftiness of knowledge, Hawthorne offers a way out of the epistemic Preface: While for each $P_{i}$ there is an ordinary context relative to which $a$ knows that $P_{i}$, there is no ordinary context in which $a$ knows each $P_{i}$, and hence no ordinary context in which $a$ knows the conjunction of all the $P_{i}$. The former is supposed to explain why we find the individual knowledge ascriptions plausible, the latter seeks to account for the fact that we find ascribing knowledge of the conjunction implausible (or less plausible), and the two explanations combine without contradicting epistemic Closure.

The crux is Hawthorne's idea that, as we run through the sequence $P_{1}, \ldots, P_{n}-$ ascribing to $a$ first knowledge that $P_{1}$, then knowledge that $P_{2}$ etc. - with each step the context slightly changes and with it the set of relevant counter-possibilities. This is compatible with holding on to epistemic Closure, contextualistically qualified: For any two propositions $P$ and $Q$ such that $a$ knows $P$ and knows $Q$ relative to one and the same context $c$, Closure allows us to infer that, in $c, a$ knows the collective consequences of $P$ and $Q$ (or is in a position to know them, or is rational only if $a$ knows them, etc.).

Returning to the Preface for credence, what if we try the hypothesis that ascriptions of rational credence exemplify the same kind of context-sensitivity that Hawthorne claims for knowledge ascriptions? The proposal would be to say that, although for each $P_{i}$ there is an ordinary context in which $a$ is rationally certain that $P_{i}$, there is no ordinary context in which $a$ is rationally certain of each $P_{i}$, and thus no ordinary context in which $a$ is rationally certain of their conjunction. Given rationality assumption (4), this would amount to a rejection, or at any rate a qualification, of the paradox's first assumption:

(1) ( $a$ is certain that $P_{1}$ ) and ( $a$ is certain that $P_{2}$ ) ... and $a$ is certain that $P_{n}$.

In particular, the Contextualist solution rejects (1) on a reading on which each conjunct of this long certainty ascription is indexed to the same context. Indeed, more generally, it rejects (1) on any reading on which many conjuncts are indexed to the same context.

This poses the question: How many conjuncts of (1) may be indexed to the same context in order for (1) to be still acceptable by the lights of the Contextualist solution (given (4))? One of the controlling mechanisms that pulls us into the paradox is that, 
the higher the number of $a$ 's body certainties, the stronger the intuition that one of them is false, the stronger the intuition that $a$ will/should have a positive credence in their Preface proposition. Reframed in terms of contexts: the higher the number of $a$ 's body certainties in $c$, the stronger the intuition that in $c$ a will/should have a positive credence in their Preface proposition (indexed to $c$ ). The Contextualist approach seeks to bring this intuitive mechanism to a halt by keeping said number low, per context. So in this sense, the less conjuncts of (1) are indexed to the same context, the more acceptable (1) becomes by the lights of the Contextualist approach.

In order for this approach to work in full generality, it cannot allow that $a$ be rationally certain of many things in one context. In spirit, this already amounts to a rejection of Abundancy. Reframed in terms of contexts, the idea underlying that principle was that there are many contexts in which we are rationally certain of many things; not that there are many things such that for each there is a context in which we are rationally certain of it.

Given that any solution to the Preface will have to reject some plausible principle, the mere circumstance that the Contextualist approach is coerced to reject Abundancy cannot be used against it. That said, this coercion is a cost on the part of the approach. Arguably, Abundancy is about as plausible for rational certainty as it is for knowledge. And let's not forget Lewis' (1996, p. 549) dictum on the Moorean nature of epistemic Abundancy.

We have all sorts of everyday knowledge, and we have it in abundance. To doubt that would be absurd. [...] It is one of those things that we know better than we know the premises of any philosophical argument to the contrary.

The preservation of this principle of epistemic Abundancy was one of the chief theoretical aims of Lewis' Contextualism. Of course, speaking from the vantage point of that theory, we will have to qualify the principle by saying that we have all sorts of knowledge in everyday contexts, notwithstanding the fact that this knowledge evaporates as soon as we enter a skeptical context that leads us to turn our attention to various far-fetched but uneliminated error possibilities which in ordinary contexts we properly ignore. $^{7}$ That said, this Lewisean qualification at least left us with an abundance of knowledge in the vast majority of contexts. But if Hawthorne's solution to the epistemic Preface is correct, we have reason to supplement epistemic Abundancy with an even stronger qualification: Although there are many pairs of propositions $P$ and ordinary contexts $c$ such that we know $P$ relative to $c$, if we hold the context fixed it turns out that we don't know that many things after all. This sobering result might prompt one to pull a Lewis and say that the fact that we have an abundance of knowledge is one of those things we know better than the premises of any linguistic theory entailing the contrary. Likewise for the Abundancy of rational certainty.

As Hawthorne (2002, p. 251) is the first to admit, his solution posits "rapid context shifting where, initially, context shift was far from noticeable." Indeed, on his conception no more is required for a knowledge-affecting shift to take place than

\footnotetext{
7 Note that the possibility that one of $a$ 's certainties is false is not one of those outlandish possibilities which the skeptic uses to demonstrate the impossibility of knowledge and/or rational certainty. To the contrary, it is a very common-sensical, near-by possibility. As a consequence, ignoring it cannot be justified in terms of Lewis' standard recipe.
} 
our moving from the question whether $a$ knows that snow is white to the question whether $a$ knows that grass is green. ${ }^{8}$ The hyperactivity with which contexts shift on Hawthorne's refined theory goes far beyond anything predicted by Lewis' unrefined theory, not to mention any other prominent contextualist theory. The only reason Hawthorne offers for believing in eratic shifts of the above kind despite their lack of pretheoretic observability is that their existence follows from his refinement of Lewis' solution to the epistemic Lottery Paradox. Hawthorne then shows that this revision gives us his solution to the epistemic Preface as a side-product. Interesting as these connections may be, Hawthorne's motivation for positing hyperactive context shifting will exert little force on those of us who prefer a solution to the Lottery other than Lewis' in the first place. ${ }^{9}$

My reply to the considered Contextualist approach to the credal Preface then is this: Even if ascriptions of rational credence show the same context-sensitivity as ascriptions of knowledge, the claim that the latter are nearly as context-sensitive as Hawthorne suggests is not sufficiently motivated. This is not an argument against the truth of his suggestion, but merely a plea for more and stronger reasons to accept the suggestion despite its quite counterintuitive consequences. Pending such motivating efforts, the approach cannot be considered a successful solution to the Preface for credence.

\section{Sensitivism about credence}

According to Sensitivism about credence, as defended by Clarke (2011, 2013), an agent's credences are sensitive to just those factors of context which Contextualists claim are relevant to the semantics of normative cognitive vocabulary such as 'know' (or 'rational', for that matter): in particular, whether the agent has credence $r$ towards $P$ in context $c$ depends on the not- $P$ alternatives salient to the agent in $c$, as well as on the practical importance of $P$ for the agent in $c$. (See Clarke 2011, ii.) Clarke (2015) claims that Sensitivism is equipped to solve the Preface Paradox. The version of the paradox he considers is a doxastic one insofar as it is framed in terms of belief. That said, Clarke happens to be one of the few who read 'belief' as denoting a credence of 1 (see Clarke 2013), which makes his version roughly equivalent to our credal version, modulo our weakening of assumption (2). I say 'roughly' to foreshadow a significant difference regarding inventory assumption (3). Anyway, we will be so cooperative as to follow Clarke's certainty interpretation of 'belief'.${ }^{10}$

\footnotetext{
${ }^{8}$ Hawthorne has little wiggle room to avoid this consequence if his solution is to apply to a version of the Preface that instantiates $P_{1}, \ldots, P_{n}$ with the proposition that snow is white, the proposition that grass is green, etc. And there is nothing about the paradox that keeps us from so instantiating its propositional variables.

9 In my case, that would be Smith's (2016, p. 51ff.) normalcy based approach, which mutatis mutandis applies to the Lottery in its epistemic, doxastic, or credal form.

10 Recall that when Clarke (2013,p. 11) argues that credence 1 (and hence belief) does not require certainty, he uses a notion of certainty on which certainty is or requires "stability of opinion". That is not the notion of certainty intended here. On our terminology as on most others', it is definitionally true that credence 1 requires certainty.
} 
Looking at things through the Sensitivist lens, Clarke suggests that, although superficially it may seem like an agent plausibly believes that one of their (other) beliefs is false, a more careful analysis reveals that this sort of Preface belief is typically held in a different context than the body beliefs it is about. In a context where $a$ is concerned with, say, the issue as to what 15 th century Europe was like, and engages in standard methods of gathering and perhaps evaluating information pertaining to that issue, $a$ unqualifiedly believes, say, that there were crusades going on back then, that more people moved into the cities, that emperor and pope tended to have opposing ideas about each others' ranges of authority, etc. Of course, $a$ may stop and reflect on body contexts of this kind - in effect launching a Preface context—and in the course of doing so attend in particular to the possibility that $a$ has misjudged at least part of the historic evidence, or alternatively that at least part of the historic evidence is misleading, and that for one of these reasons one of the beliefs $a$ holds about 15th century Europe is false. Moreover, $a$ may not only consider this a possibility but a fact virtually guaranteed by the ordinary kind of human fallibility that characterizes both $a$ and $a$ 's informants.

However, Clarke (2015, p. 374) argues, the body context in which $a$ holds their historic beliefs and the Preface context in which $a$ reflects on their human fallibility are distinct. In a body context where the focus is on 15 th century Europe, $a$ 's fallibility is simply not the topic, and $a$ is not plausibly describable as believing that one of their beliefs about 15th century Europe is false. On the other hand, in a Preface context where $a$ 's fallibility becomes topical, $a$ is not plausibly describable as still holding the cited beliefs about 15th century Europe. Instead, what $a$ will believe about that topic in a Preface context are probabilistically weakened propositions to the effect that it's very likely that there were crusades going on, that its' very likely that more people moved into the cities, etc. (See ibid., p. 375.) But it is not those weakened propositions that form the domain of $a$ 's Preface belief, but rather their unqualified counterparts: In the Preface context $a$ believes that one of the things a usually believes is false, i.e. one of the things $a$ believes in a body context. That is, per context, $a$ 's beliefs are mutually consistent, at least as long as $a$ 's body beliefs are consistent and $a$ refrains from believing in a context that one of the things they believe in that very context is false. Clarke then argues that the norm of Consistency is plausible only as an intra-contextual norm, not as a cross-contuxtual norm. (See ibid., pp. 364, 368, 374f.)

This suggests that Clarke would reject (2') on an intra-contextual reading on which it says that in $c, a$ has a positive credence that one of their certainties in $c$ is false; but would accept (2') on an inter-contextual reading on which it says that in $c, a$ has a positive credence that one of their certainties in $c^{\prime}$ is false. As regards (1), unlike the Contextualist approach, the Sensitivist approach allows this assumption to be true with all of its conjuncts indexed to the same context (compatibly with rationality assumption (4)). As a consequence, the latter approach doesn't require nearly as far-reaching a qualification of Abundancy. This looks like progress.

But problems remain. While Sensitivist precepts enable us to deal with the Consistency side of the paradox in the manner Clarke demonstrates, they fail to provide any sort of relief as regards its Closure side. To see the problem, it is not difficult to imagine a mixed context $c^{\prime}$ in which both 15 th century Europe and $a$ 's beliefs about it are topical, to the effect that in $c^{\prime}, a$ believes not only that there were crusades going 
on, that more people moved into cities, etc., but also that $a$ believes that there were crusades going on, that $a$ believes that more people moved into cities, etc. (and also believes a corresponding inventory proposition). We may then, without changing the context, direct $a$ 's attention to the fact that the things $a$ believes in $c^{\prime}$ collectively entail that everything $a$ believes in $c^{\prime}$ about 15 th century Europe is true. How would the Sensitivist approach deal with mixed contexts of this kind?

Clarke $(2015$, pp. 369,378$)$ seems to agree that it would be unduly immodest for $a$ to believe that all of their beliefs are true, even though this proposition is a logical consequence of $a$ 's beliefs in the mixed context. He emphasizes that, although $a$ doesn't believe the Preface proposition in a body context, $a$ also doesn't believe its negation in any ordinary context, be it of the body or the Preface kind. But that concession fails to mitigate the worry that, when confronted with a logical consequence of one of one's beliefs, one should form a belief in that consequence or revise one's belief set. It just seems paradigmatically irrational to refuse to believe a consequence of one's beliefs in a context where one is both aware that one holds those beliefs and that they have this consequence. At least this is so where 'belief' is understood as denoting a credence of 1 , which, again, is an interpretation Clarke accepts.

It thus turns out that the Sensitivist approach is committed to rejecting Closure, or to somehow restricting it. That is not a problem per se, since, again, any solution to a genuine paradox must reject at least one plausible assumption (or inference). But while necessary, that measure is not sufficient to solve a paradox. An approach must be able to explain, in a way consistent with the falsity (invalidity) of the rejected assumption (inference), why the latter so much as seems to be true (valid). Otherwise the approach will fail to explain away one of the intuitions keeping the paradox alive. To the extent that considerations of context-sensitivity have implications pertaining to the issue of Closure at all, all they suggest is that this principle should be viewed as an intrarather than inter-contextual norm, in the same way that Clarke restricts the validity of Consistency to intra-contextual applications. But even with Closure qualified in this way, the Sensitivist approach is committed to rejecting it; after all, the mixed context worry only involved one context. Thus, the first problem for the Sensitivist approach is that, while forced to reject Closure (even with antecedent and consequent indexed to the same context), it fails to explain away its intuitive appeal. ${ }^{11}$

Could Clarke make the rejection of Closure plausible by invoking the familiar Demandingness objection to this principle? (See e.g. Cherniak 1986, p. 93.) The objection starts with the observation that believing all logical consequences of even a fairly modest belief set would outstrip the computational capacities of any finite agent, and concludes that any rule to the effect that $a$ 's belief set should be logically closed would be too tall an order. In effect, this inference presupposes that Ought implies Can, or that the normativity of a rule requires an ability in principle to comply with it. We may concede that there's little point in criticizing $a$ for violating logic or, for that matter, probability theory where that violation is a mere byproduct of $a$ 's limited cognitive abilities; and also that the kind of normativity appealed to in legitimate cases

11 Clarke (2015, pp. 365, 373f.) argues against rejecting Consistency by arguing that the norm (relativized to contexts) is required to explain the normative force of deductive arguments. But if that is the phenomenon to be explained, the (similarly contextually relativized) norm of Closure is arguably just as much needed. 
of criticism does presuppose an ability on the part of the subject of criticism to conform with the norm in question.

However, that much is compatible with the claim that logic and probability theory are normative in the sense that, the more $a$ 's beliefs and credences are in harmony with those theories - in particular, the closer $a$ comes to satisfying the structural requirements of Consistency, Closure, and Coherence in general - the better $a$ 's performance in rational respect. The kind of normativity relevant to doxastic and credal norms such as the ones just named is the kind relevant to evaluating rather than criticizing $a$ 's performance, and that kind of Ought does not imply Can. Suppose $a$ and $b$ are confronted with the same Total Evidence and both form the same degrees of certainty with regard to the same propositions in response to that evidence; the only difference being that $a$ validly infers more propositions from the set of propositions they are both certain of than does $b$, to the effect that $a$ becomes certain of those further propositions while $b$ doesn't (perhaps by way of not even considering them). One plausible thing to say about this setting is that $a$ is being more rational than $b$, ceteris paribus. Here it is irrelevant whether $b$ 's shortcoming has its explanation in $b$ 's lesser computational capacities compared to $a$ 's, or in $b$ 's inattentiveness, or what have you. Violating Closure by failing to draw the inferences that $a$ draws may be excusable for $b$, if drawing those inferences would overcharge $b$ 's intellectual resources or if $b$ is just not paying attention for whatever reason, but that doesn't make it rationally permissible for $b$ to violate Closure in any sense of permissibility undermining the comparison just made. It is hard to deny that $a$ has got some kind of edge over $b$ in the rationality department. And the norm of Closure enables us to make that comparative judgment, without making any sort of unreasonably high demand. The Demandingness objection to Closure is thus beside the point, as would be any defense of the Sensitivist approach based on it.

Near the very end of his (2015) paper, after presenting his official Sensitivist solution, Clarke considers an objection centered on a scenario similar to our mixed context case, one that has the agent consider all at once and in the same context their evidence for their individual body propositions and their (inductive) evidence for one of them being false. In reply, Clarke notes that he finds this form of the paradox less interesting than his, for the reason that the Preface situation is only plausibly paradoxical if the relevant set of body propositions is sufficiently voluminous, and that an agent who can consider all the elements of such a set at once is not much like us humans. With equal right, Clarke could give an analogous answer to our mixed case objection. But I have already argued that cognitive limitations are irrelevant to considerations about what $a$ should believe or have credence 1 in, in any sense of 'should' geared to evaluating rather than criticizing $a$ 's performance. Moreover, it's not obvious that the complexity a set of propositions requires in order to make its Preface proposition plausible must be higher than the complexity of any set of propositions an ordinary human could consider at once. (For a quite instructive counterexample, see Smith 2016, p. 72f.)

And even if we concede this point for the sake of argument, we should not agree that the amount of idealization involved in the assumption that $a$ considers all elements of a relevant body belief/certainty set at once is so great that it renders the resulting argument uninteresting. One of the most pressing questions the Preface gives rise to is whether it is possible in principle for our rational norms to come into conflict with 
one another. If the answer is "yes, but the conflict will never become acute due to our limited attention spans", that would be interesting enough. Since the conflict, if it is one, can be made explicit only in terms of the idealized version of the paradox, that makes the latter more interesting, theoretically, than Clarke's non-idealized one.

Clarke (2015, p. 377f.) goes on to speculate:

Perhaps, though, the point of this [idealized] version of the paradox is supposed to be that an ideally rational version of $[a]$ should have inconsistent beliefs. I think even this is wrong: it is not the case that $[a]$ ought to believe inconsistently if she were to consider the totality of her evidence about the body claims and about her own fallibility in a single context, because evidence of the latter sort undermines beliefs of the former sort. If $[a]$ is thinking seriously about her own fallibility, then she ought not to believe any of the body claims outright, though she ought still to believe things in the neighborhood: where $p$ is one of the body claims, she ought not believe that $p$, but that probably $p$, or that $p$ is most likely given her evidence.

Speaking for myself, the point of making idealizing inventory assumption (3) is not to argue for the claim that an ideally rational version of $a$ should have inconsistent beliefs or be in an incoherent credal state, but merely to highlight what sort of consideration lends this claim prima facie plausibility; which after all is an indispensable part of understanding the dialectical currencies surrounding the paradox. This is not to dispute anything Clarke says in his objection to the claim. In a nutshell, his objection is that evidence in support of $a$ 's Preface proposition defeats $a$ 's justification for believing their body propositions. The idea is roughly reminiscent of Pollock's Global Defeat approach to the Lottery Paradox. ${ }^{12}$ Modified so as to apply to the Preface for credence (and filtering out various details of Pollock's complex theory of defeat) the approach can be roughly outlined as follows:

Assume $a$ 's Total Evidence $E$ satisfies the following three conditions. (i) For each $P_{i} \in\left\{P_{1}, \ldots, P_{n}\right\}$ there is a subset $E_{i} \subseteq E$ defeasibly justifying $a$ in being certain that $P_{i}$. (ii) There is a subset $E^{\prime} \subseteq E$ justifying $a$ in being certain of $a$ 's inventory proposition. (iii) There is a subset $E^{*} \subseteq E$ justifying $a$ in having some credence above 0 in their Preface proposition. Then for each $P_{i}, E^{\prime} \cup E^{*}$ defeats $a$ 's justification for being certain that $P_{i}$. What $a$ is left with is justification to have a credence of $r$ in $P_{i}$, where $r$ is still high (the higher $n$, the higher $r$ ) but less than 1 , so that the credence which the probability calculus requires $a$ to adopt towards the conjunction of all the $P_{i}$ leaves enough room for a credence above 0 in its negation. ${ }^{13}$ Thus, the rational thing for $a$ to do is to lower their credences over $\left\{P_{1}, \ldots, P_{n}\right\}$ accordingly, thereby

\footnotetext{
12 Incidentially, Pollock (1986) himself resists applying the strategy of Global Defeat to the Preface, for the reason that $a$ 's body propositions are not mutually negatively relevant, as opposed to lottery propositions. Note however that there is a relation of mutual negative relevence between the set containing both $a$ 's body propositions and their corresponding inventory proposition on the one hand and $a$ 's Preface proposition on the other.

${ }^{13}$ For simplicity, I am assuming that all the $P_{i}$ are probabilistically independent, and also that $a$ 's certainty in $P_{1}, a$ 's certainty in $P_{2}, \ldots$, and $a$ 's certainty in $P_{n}$ are all equally well justified. Lifting the second assumption would require refining the approach in the spirit of Smith's (2020) Differential Defeat.
} 
falsifying (1). Given our idealizing stipulation that $a$ is fully aware of their credences, this would in turn falsify (3), and also make (2') implausible, given (4).

This is an interesting proposal, or at least the root of one. Note however that Sensitivism plays no role in it. Instead, all the theoretical work is being done by considerations about evidential balancing and probabilistic Coherence, irrespective of non-evidential features of the context such as stakes or salience. In sum, Clarke's Sensitivist solution is tailored to solve a non-idealized version of the Preface that I have argued is less interesting than the idealized version; and when it comes to the latter, Clarke falls back on a Global Defeat approach. ${ }^{14}$

Putting it in more positive terms, the Sensitivist approach can be thought of as a synthesis of two opposed approaches, allocated to different types of context: hardheaded anti-skepticism for body contexts, Global Defeat for Preface contexts. But then we cannot but note an oddity about this synthetic approach's economics, one that becomes apparent when comparing its costs and benefits to those of the pure and uncompromised Global Defeat approach. Both offer the benefit of saving Consistency, so this common factor cancels out. But Global Defeat also preserves Closure for certainty (and indeed Coherence for credence in general), whereas the Sensitivist approach is forced to abandon it or otherwise restrict it in some non-ad hoc manner yet to be revealed (likewise for Coherence in general). So far, this is an advantage, at least pro tanto, for Global Defeat. It might seem as if the advantage could be outweighed by the fact that Global Defeat has the undisputed cost of sacrificing Abundancy, while prima facie the Sensitivist approach manages to avoid that particular drawback. But this apparent advantage on the part of the latter turns out to be merely apparent: Even from a Sensitivist view point we have to concede that, if $a$ were to think just a little bit harder about their own Preface proposition and their evidence for it, $a$ would have to come to the realization that the propositions they are certain of are actually only extremely likely, due to the non-zero probability of $a$ 's Preface proposition. So we have a tie over Consistency and Abundancy, while pure Global Defeat has the upper hand over its Sensitivist rival when it comes to Closure (and hence Coherence). I submit that the Sensitivist approach shows a less optimal balance of costs and benefits than one of the approaches it incorporates does in isolation.

While I see no way around this problem, there is a second issue that threatens to make the Sensitivist approach less than satisfactory. According to Clarke, at least to the extent that $a$ is rational, $a$ won't believe, i.e. have credence 1 in, their own Preface proposition. But in order to stay out of trouble, it's not enough that $a$ stays clear of adopting a credence of 1 in that proposition. All that would accomplish is keeping $a$ 's certainty set free of inconsistency. The latter however is not the only unattractive feature worth avoiding. Another, more general such feature would be the incoherence of $a$ 's credal state. And in order to avoid this malum, $a$ has to avoid more than forming a credence of 1 in their Preface proposition; $a$ must avoid forming any credence other

\footnotetext{
14 Clarke's drift toward a defeat approach also becomes apparent when he (ibid., p. 376) remarks that "the Preface context represents [a's] more considered opinion". See also Clarke (ibid., p. 375): "[a] asserts the Preface disclaimer in a relatively stringent context, where certain possibilities (possibilities where her human fallibility has led to an error somewhere in the book) are attended to; these possibilities are ignored in the context where she asserts the body claims; but she regards these possibilities as more plausible than the ones attended to in the body contexts."
} 
than 0 in that proposition. However, it looks like the only way for $a$ to avoid this is to violate the Total Evidence requirement. After all, intuitively, $a$ 's Preface proposition seems to be better supported (inductively) by $a$ 's Total Evidence than any proposition that, in the light of that evidence, would deserve a credence as low as 0 . There is thus a real question to what extent accepting Clarke's solution is compatible with holding on to Total Evidence. The latter requires that $a$ 's credences respect $a$ 's entire evidence rather than some contextually salient subset thereof. Clarke has taken no step toward explaining away the plausibility of this principle. ${ }^{15}$

For the sake of contrast, consider once again the partially overlapping but less complex Global Defeat approach, based on the simple and unqualified core claim that the kind of evidence $a$ has for their Preface proposition (supplemented with the evidence $a$ has for their inventory proposition) defeats the evidence justifying $a$ 's certainty in their body propositions. This claim leads to a rejection of Abundancy (via a rejection of (1) conditional on rationality assumption (4)). But Global Defeat is in a position to explain the prima facie plausibility of this principle in terms of our cognitive limitations and our unsurprisingly resulting habit of basing our credences in individual propositions not on our evidence in its totality (as we ideally ought to), but on whatever fraction of it strikes us as relevant in the context in question. Should the Sensitivist approach indeed prove unable to avoid a commitment to rejecting Total Evidence, the fact that the approach lacks any analogous error-theoretic explanation of this principle's plausibility will turn that commitment into a further entry on the approach's list of costs, which we have already seen to outnumber those on the part of pure Global Defeat.

\section{Conclusion}

What our discussion has shown is that the task of making considerations of contextsensitivity available as a tool for solving the Preface for credence is far from trivial. Attempts to build on the model of existing approaches in this vein either have to assume forms of context-shifting that are more hyperactive than experience or inference to the best explanation seem to confirm, or are forced to reject apparent principles of rationality without being able to explain away their intuitive appeal. At least tentatively this points to the conclusion that, unpopular as the Global Defeat approach may be within the debate about the Preface for belief, it or something very similar to it may well be our only way out of the Preface for credence; offering us a reason against Abundancy that is rooted neither in skepticism nor in the betting model of credence.

Acknowledgements For comments and constructive criticism I am grateful to Alexander Dinges, Ali Esmi, André Fuhrmann, and three anonymous referees for Synthese. Special thanks to Martin Smith and Stephen

\footnotetext{
15 This problem won't go away even if we adopt a Contextualist conception of evidence along the lines of Neta (2003). What this would allow us to say is that the extent to which $a$ 's Preface proposition is supported by $a$ 's evidence may change with context, and in particular may be lower in a body context while higher in a Preface context. The reason why this strategy won't work is that even in a body context, the evidential backing of $a$ 's Preface proposition is arguably never quite so low as to justify a credence of 0 , even by the most ordinary and non-skeptical standards.
} 
Yablo. My work on this paper was supported by a Research Fellowship (KA 4883/1-1) granted by the German Research Foundation.

Funding Open Access funding enabled and organized by Projekt DEAL.

\section{Compliance with ethical standards}

Conflict of interest The authors declare that they have no conflict of interest.

Open Access This article is licensed under a Creative Commons Attribution 4.0 International License, which permits use, sharing, adaptation, distribution and reproduction in any medium or format, as long as you give appropriate credit to the original author(s) and the source, provide a link to the Creative Commons licence, and indicate if changes were made. The images or other third party material in this article are included in the article's Creative Commons licence, unless indicated otherwise in a credit line to the material. If material is not included in the article's Creative Commons licence and your intended use is not permitted by statutory regulation or exceeds the permitted use, you will need to obtain permission directly from the copyright holder. To view a copy of this licence, visit http://creativecommons.org/licenses/by/4.0/.

\section{References}

Beddor, B. (2020). Certainty in action. The Philosophical Quarterly, 70(281), 711-737.

Cherniak, C. (1986). Minimal rationality. Cambridge: MIT Press.

Christensen, D. (2004). Putting logic in its place: formal constraints on rational belief. New York: Oxford University Press.

Clarke, R. (2011). Belief in context. Dissertation, published online at https://open.library.ubc.ca/cIRcle/ collections/ubctheses/24/items/1.0072488.

Clarke, R. (2013). Belief is credence 1 (in context). Philosophers' Imprint, 13(11), 1-18.

Clarke, R. (2015). Preface writers are consistent. Pacific Philosophical Quarterly, 98, 363-381.

Cevolani, G. (2017). Fallibilism, verisimilitude, and the preface paradox. Erkenntnis, 82, 169-183.

Easwaran, K., \& Fitelson, B. (2015). Accuracy, coherence, and evidence. Oxford Studies in Epistemology, $5,61-96$.

Easwaran, K. (2016). Dr. Truthlove or: How i learned to stop worrying and love Bayesian probabilities. Nous, 50(4), 816-853.

Eriksson, L., \& Hájek, A. (2007). What are degrees of belief? Studia Logica, 86(2), 185-215.

Evnine, S. J. (1999). Believing conjunctions. Synthese, 118(2), 201-227.

Foley, R. (1992). The epistemology of belief and the epistemology of degrees of belief. American Philosophical Quarterly, 29(2), 111-124.

Frankish, K. (2009). Partial belief and flat-out belief. In F. Huber \& C. Schmidt-Petri (Eds.), Degrees of belief (pp. 75-93). Dordrecht: Springer.

Ganson, D. (2008). Evidentialism and pragmatic constraints on outright belief. Philosophical Studies, 139(3), 441-458.

Greco, D. (2013). Possibility and prodigiality. In T. Szabó Gendler \& J. Hawthorne (Eds.), Oxford studies in epistemology (vol. 4, pp. 82-107). Oxford: Oxford University Press.

Hawthorne, J. (2002). Lewis, the lottery and the preface. Analysis, 62(3), 242-251.

Joyce, J. (2009). Accuracy and coherence-prospects for an alethic epistemology of partial belief. In F. Huber \& C. Schmidt-Petri (Eds.), Degrees of Belief (pp. 263-297). Dordrecht: Springer.

Kaplan, M. (1996). Decision theory as philosophy. Cambridge: Cambridge University Press.

Kaplan, M. (2013). Coming to terms with our human fallibility: christensen on the preface. Philosophy and Phenomenological Research, 87(1), 1-35.

Kauss, D. (2020). Credence as doxastic tendency. Synthese, 197, 4495-4518.

Leitgeb, H. (2013). Reducing belief simpliciter to degrees of belief. Annals of Pure and Applied Logic, 164(12), 1338-1389.

Levi, I. (1983). Truth, fallibility and the growth of knowledge. In R. S. Cohen \& M. W. Wartofsky (Eds.), Boston studies in the philosophy of Science (Vol. 31, pp. 153-174). Dordrecht: Springer.

Lewis, D. (1996). Elusive knowledge. Australasian Journal of Philosophy, 74(4), 549-567. 
Maher, P. (1993). Betting on theories. Cambridge: Cambridge University Press.

Makinson, D. (1965). The paradox of the preface. Analysis, 25(6), 205-207.

Makinson, D. (2012). Logical questions behind the lottery and preface paradoxes: Lossy rules for uncertain inference. Synthese, 186, 511-529.

Nelkin, D. (2000). The lottery paradox, knowledge, and rationality. Philosophical Review, 109(3), 373-409.

Neta, R. (2003). Contextualism and the problem of the external world. Philosophy and Phenomenological Research, 66(1), 1-31.

Pollock, J. L. (1983). Epistemology and probability. Synthese, 55(2), 231-252.

Pollock, J. L. (1986). The paradox of the preface. Philosophy of Science, 53(2), 246-258.

Ross, J., \& Schroeder, M. (2014). Belief, Credence, and Pragmatic Encroachment. Philosophy and Phenomenological Research, 88(2), 259-288.

Ryan, S. (1991). The preface paradox. Philosophical Studies, 64(3), 293-307.

Smith, M. (2016). Between probability and certainty: What justifies belief. Oxford: Oxford University Press.

Smith, M. (2020). The hardest paradox for closure. Erkenntnis. https://doi.org/10.1007/s10670-020-002874.

Sturgeon, S. (2008). Reason and the grain of belief. Noûs, 42(1), 139-165.

Thomson, J. J. (1986). Liability and individualized evidence. Law and Contemporary Problems, 49(3), 199-219.

Publisher's Note Springer Nature remains neutral with regard to jurisdictional claims in published maps and institutional affiliations. 